\title{
2 \\ Talking language: A tribute to Ken Hale
}

\author{
Peter Sutton
}

\section{A little history ${ }^{1}$}

In 1960 Ken Hale spent 1-17 August at Aurukun Presbyterian Mission, Cape York Peninsula, recording basic materials in five different languages. These included the northern Paman language Linngithigh, and the Wik Subgroup varieties Wik-Ep/Wik-Me'enh, Wik-Ngatharr, Wik-Mungkan, and Kugu Muminh, the latter being a variety of Kugu Ngancharra. His consultants included Sam Kerindun (Linngithigh), Joe Marbendinar (Wik-Ep/Wik-Me'enh, Wik-Ngatharr, Wik-Mungkan), Jim Henry (Wik-Mungkan), and Billy Ngakapoorgum (Kugu Muminh). ${ }^{2}$ Given that Ken spent such a short time there, it is remarkable that Aurukun people have remembered him 'talking language' with them in a competent way, long after the event. ${ }^{3}$

In about 1976, Ken sent a taped message in one of the languages, Linngithigh, to Fred Kerindun, the son of Sam Kerindun, the latter having passed away by then. Sam had been one of Ken's main linguistic

\footnotetext{
1 An earlier version of this chapter appeared as Sutton (2001).

2 The dates of Ken's visit are derived from the Aurukun Mission Diary (MS2483, AIATSIS Library, Canberra). Information about Ken's consultants is from copies of his field notes (MS4114, AIATSIS Library, Canberra). Aurukun ceased being a mission, and became a local government area township, in 1978 .

3 'All thought it a prodigious achievement', John von Sturmer (pers. comm.).
} 
consultants at Aurukun. His was a phonologically difficult Northern Paman language with little overt resemblance to the Wik Subgroup languages Ken also studied in this instance. ${ }^{4}$ The Aurukun people's perception that Ken's ability to absorb a language was extraordinary was no exaggeration.

The Aurukun Mission diary of the day, chiefly maintained by Superintendent Reverend William MacKenzie, was rather more offhand in its response to Ken's visit. Bill MacKenzie was, according to his own record, a 'cot case' with ill health for most of Ken's time at Aurukun, but his diary entries for this period were no different from the usual. Records such as 'grind valves and re-cut seats on kerosene engine' or 'repaired broken brake-line Ford Blitz' were common. It is of note that MacKenzie's entries moved from referring to 'Dr Hale' to 'Ken Hale' by late in Ken's visit, probably a sign of something positive in MacKenzie's reception of Ken. It was certainly in contrast with MacKenzie's use of the formal 'Mr McCarthy' all the way through the Aurukun diary entries covering Frederick McCarthy's ethnological visit to Aurukun 16-29 November 1962, for the AIAS. That visit was cut short when MacKenzie arranged for the manager of the nearby Weipa mine to fly McCarthy out before his expected field time had expired. Earlier MacKenzie had come into conflict with anthropologists then working in the area (Ursula McConnel in 1927, Donald Thomson in 1933). Both were banned from visiting Aurukun.

\section{Aurukun mission diary entries about Ken Hale}

Monday 1 August 1960:

Watt Leggatt [Presbyterian Mission lugger, probably coming from Mornington Island Mission] arrived 5.30. Ted Butler, Dr Hale, Gully, Pompey, Prince, Larry \& Dick. ${ }^{5}$ Had good trip.

\footnotetext{
4 See Hale (1964, 1966, 1997a).

5 These men were probably: Ted (E.C.) Butler, missionary; Aboriginal men Gully Peters, Pompey Wilson, Prince Escott, Larry Lanley and Dick Roughsey, from Mornington Island. Ken Hale spent two months there between July and October 1960 (Ngakulmungan Kangka Leman 1997:3-6). The Aurukun and Weipa visits seem to have been interpolated into this more extensive field work.
} 
Tuesday 2 August 1960:

Dr Hale had Sam Kerindun to help him with Lengitie $e^{6}$ language, also Polly [Blowhard].

Friday 12 August 1960:

Dr Hale still working with Sam

Sunday 14 August 1960:

Jack $^{7} \&$ Ken Hale went to Wutan afternoon load girls to pick up coconuts.

Wednesday 17 August 1960:

Reliance [Aurukun Mission boat] away 7.30. Ted Butler \& Ken Hale went up [presumably to Weipa], also 3 Mornington men.

And that is it. Ken went on to Weipa. The people Ken worked with at Weipa, whose languages were all Northern Paman, included: Tictic (language: Yinwum), Frank Moreton (Ngkoth), Andrew Mark (Arrithinngithigh), Willie (Mbiywom), Robert Hall (Ndrrwa'angith), Monty Motton (Ndrra'angith), Arthur Dick (Mamngayth), Hector (Ndrrwa'angayth), and Keepas (Alngith(igh)). ${ }^{8}$

As in most other cases dealt with here, the main language consultant was usually both a full owner of the variety concerned, not merely a competent speaker of it, and a, if not the, politically pre-eminent member of his or her land-holding group. I take this to be an index of the cultural and political importance attached to acting in this language teaching role in that era. It is notable that many other scholars' linguistic and anthropological consultants have been local 'bosses'.

Meanwhile, back at Aurukun, there had been an intriguing mission diary entry about an outbreak of mild Bolshevism, which occurred just after Ken left for Weipa.

6 i.e. Linngithigh (lexicon published as Hale 1997a).

7 Jack was probably a mission staff member.

8 No dates or places are provided in the field notes that I have seen (MS4114, AIATSIS Library, Canberra). I have respelled personal names here to be as they were most often officially recorded, and have added surnames where I know who the people were from my own work in the area. 
Saturday 20 August 1960:

People wanted talk with Rev Sweet ${ }^{9} \&$ self. Some grievances over no work. Mostly of infantile nature. Denny B re store wages. Morrison re wages. Allan re child endowment. Paul ${ }^{10}$ re people having children - repercussion from Mornington Islanders. Went on till 1.15. J.R.S. [Rev Sweet] explained shortage of money. Most of the men very loyal ... Sam [Kerindun] offered that people's Communion offering be devoted to money shortages. RS [Rev Sweet] very graciously thanked him but that would not be enough.

The MacKenzie regime was very autocratic, morally strict and at times dished out corporal punishments decided upon by the Superintendent. Ken was a left-of-centre modern. I can't help guessing there may have been a causal link between Ken's 16 days at Aurukun and the lodging of multiple grievances three days later.

\section{Cultural implications of 'talking language'}

One day in about 1976 a Wik man, Peter Peemuggina, asked me if I knew a 'Doctor Keneyl', and, if so, how and where was he? I replied to Peter that I did indeed know Ken, who was often at home in America.

This was not the last time Wik people inquired after Ken or brought his name up in conversation, the most recent to my knowledge being in 1999. ${ }^{11}$ He clearly made a significant impact on them. They also spoke of the anthropologists Ursula McConnel and Donald Thomson, who had spent many months living among Wik people in the 1920s and 1930s. It was understandable that these two long-stayers would be remembered. Stories about them were told and retold by fires on the long evenings of quieter days, by those who had known them personally. In terms of the time he had spent there, Ken was just another short-term visitor whose name and identity would normally have been forgotten like all the others, but this was not how people saw it at all.

9 The Reverend James R. Sweet.

10 i.e. Denny Bowenda, Morrison Wolmby, Alan Wolmby and Paul Peemuggina, all 'Cape Keerweer' (lower Kirke River system) men.

11 Amanda Reynolds (pers. comm.). Peter Peemuggina was still alive at the time of writing, i.e. 2021. 
What made the difference, as I understand it, was Ken's ability to speak local languages, at least to an extent and well, in a phenomenally short time. No doubt another factor would have been Ken's capacity to relate to the people from whom he was learning. The very act of approaching their languages with seriousness, and taking the trouble to study them carefully, combined with what was probably a rather startling ability to sound like he was born there, would all have smoothed the way to being memorable.

I doubt, though, that even this feat alone would perpetuate such memories of a brief visit four decades later. I think a deeper and specifically Aboriginal cultural factor is also at work here.

In a small-scale society it is possible, and in fact in Cape York Peninsula it was highly likely under classical cultural conditions, that an adult would personally know and be genealogically related to everyone else who shared a common primary language affiliation, especially at the level of the named language variety. ${ }^{12}$ In the Wik Region this was the case whether the affiliation was at the level of the small patrifilial clan groups, which averaged around 20 or so members, which are dialect-holding entities, or at the level of the proper-named linguistic varieties shared by a number of different clan groups, or even at the level of linguistic macro-groupings, which are based on a recognition of degrees of grammatical and lexical similarities between sets of separately named varieties.

In addition, in the Wik Region, as in so many other parts of Aboriginal Australia, the mere fact that someone can speak the same language as oneself is usually taken to imply that the other person must be kin, related to ego somehow or another, in either an actual or a classificatory sense. In the absence of disputation the default relationship to one's kin is one of underlying amity. There is also a common view that linguistic competence in an Aboriginal language by a non-Aboriginal person must imply not only cultural competence and understanding, but also an acceptance of the worth of Aboriginal culture itself and thus of its peoples.

When a non-Indigenous person is heard speaking an Aboriginal language-a situation still rare in Australia outside the Western DesertAboriginal people are usually quickly of the view that this person has

12 Actually, not all Cape York Peninsula language varieties had names, but in those cases known to me the different varieties could still be identified by salient linguistic characteristics (e.g. different words for 'no'), or by references to the main totem of a clan owning the variety, or by a 'big country name' for an area the language belonged to. 
in some significant way entered into their world of values, their web of relationships, their patchwork of country identities, and furthermore that this is someone who does not look down on them, who is not 'stuck up'.

People who can 'talk language', as it is so often put in Aboriginal English, speak what the ancestors spoke. The ritualised process of talking to the spirits of the 'Old People' when visiting particular places is itself often referred to in English simply as 'talking language'-because the ancient ancestors did not know English. ${ }^{13}$ To 'talk language' is not merely to make evident one's linguistic education, but in a sense it is also to reproduce the characteristic voice of the Old People who were ancestral to some particular network of kin.

A common shorthand Aboriginal expression of this recognition of outsider skills in insider matters is to say of the person that he or she 'knows'. In classical Aboriginal thought there is more to this 'knowing' than mere grammatical competence or cultural familiarity. In the Wik area, as has been documented over much of Australia, languages are held by their Aboriginal owners to have been implanted in specific countries at the foundation of the world, by heroic ancestral figures or, as they are known in Cape York Peninsula, 'Stories'. ${ }^{14}$ A small clan of anywhere between one and a few score people, in Wik thought, is itself considered a microlinguistic group with its own unique variety of speech, ${ }^{15}$ a variety that is typically specified by naming a principal totem of the clan, as explained in more detail later in this book. Language is, in this sense, at once both spiritual and political.

13 That is, 'talking language' is sometimes a shorthand idiomatic way of referring to the addressing of ancestral spirits - 'We go to place X, we talk language', i.e. 'When we go to place X, we will address the spirits in an appropriate local language'. In my experience, spirits are only rarely addressed using English. 14 One legendary account of the creation of Wik Subgroup languages is provided by Noel Peemuggina in Sutton (1997b). In that legend the named varieties are implanted estate by estate as the two culture heroes, the Pungk-Apelech (Clearwater Knees) Brothers, move across the landscape establishing totemic centres in each clan's estate. In a number of other accounts referred to in that paper, drawn from other parts of Australia, Dreaming (Story) beings implant or recognise specific languages across whole linguistic territories, typically beginning to speak a new language as each linguistic territory is entered and switching to another on departure from it.

15 Sutton (1978:138), von Sturmer (1978:325-26), Smith and Johnson (2000:366-67). 
The first people spoke these respective varieties when the world was young, and their descendants ideally speak the same way today, or at least used to. ${ }^{16}$ The highly emotional and spiritual links between one's principal ancestral language variety and the deepest reaches of local identity were made clear when naming that variety by means of the primary totemic symbol of each descent group. This, as well as the intrinsic connection between that variety and a passionately held clan country or homeland, meant that choice of speech variety was no casual matter in this society. To choose any Aboriginal speech variety, especially one other than a lingua franca (in this case Wik-Mungkan), was to immediately implicate specific areas of country and to demonstrate links to their particular people. ${ }^{17}$

In 1960, into this intense world where speech varieties resonated daily not only with the people's geopolitics but also with their cosmogony and ontology, stepped a young American who almost overnight began to speak and sound like one of their own. This was a unique experience for the Wik people of Aurukun, as it no doubt was for others elsewhere. Those who were old enough to appreciate the import of it at the time continued for decades to regard Ken Hale with enduring interest and respect, and not a little awe.

16 While a number of Wik varieties such as Wik-Me'enh and Wik-Ep are moribund, and WikNgathan and Wik-Elkenh/Wik-Ngatharr have only adult fluent speakers, Wik-Mungkan is the first language of most children at Aurukun, and some Kugu Ngancharra varieties persist reasonably well, especially at Pormpuraaw. Wik-Way varieties seem now to have only senior adult speakers of even modest competence.

17 Conversely, to mainly employ a lingua franca and abandon use of one's own speech variety also has its motivations, although in many community situations it is hard to separate motivation from necessity in this domain. 
This text is taken from Linguistic Organisation and Native Title: The Wik Case, Australia, by Peter Sutton and Ken Hale, published 2021 by ANU Press, The Australian National University, Canberra, Australia.

doi.org/10.22459/LONT.2021.02 